\title{
A new genus with two new species of lecanicephalidean tapeworms (Cestoda) from the mangrove whipray, Urogymnus granulatus (Myliobatiformes: Dasyatidae), from the Solomon Islands and northern Australia
}

\author{
Kaylee S. Herzog and Kirsten Jensen
}

Department of Ecology and Evolutionary Biology, and the Biodiversity Institute, University of Kansas, Lawrence, Kansas, USA

\begin{abstract}
A new lecanicephalidean genus is erected for cestodes previously recognised as "New Genus 12" (Polypocephalidae) in a phylogenetic analysis of the interrelationship of members of this order. Examination of the cestode fauna of the mangrove whipray, Urogymnus granulatus (Macleay) (Myliobatiformes: Dasyatidae) from the Solomon Islands and northern Australia revealed the existence of specimens representing two new species, consistent in morphology with "New Genus 12." Corollapex gen. n. is unique among the 24 valid lecanicephalidean genera in its possession of an apical organ in the form of an external retractable central disk surrounded by eight concave muscular, membrane-bound pads and an internal heterogeneous glandular component. The two new species described herein, Corollapex cairae sp. n. (type species) and Corollapex tingoi sp. n., differ from one another in overall size and number of mature and immature proglottids, and are noted to demonstrate a differential distribution between mature and juvenile host individuals. Additional species diversity in the new genus, beyond C. cairae sp. n., C. tingoi sp. n., and "New Genus 12 n. sp. 1" of Jensen et al. (2016) is suggested. Corollapex gen. n. appears to be restricted to dasyatid hosts in the Indo-West Pacific region.
\end{abstract}

Keywords: Lecanicephalidea, apical organ, scanning electron microscopy, Polypocephalidae, Indo-West Pacific region

Very little is known about the cestode fauna of the mangrove whipray, Urogymnus granulatus (Macleay), from across its range in the Indo-West Pacific region (see Last et al. 2016a). Williams (1964) described the rhinebothriidean Rhinebothrium himanturi Williams, 1964 and reported the presence of a potentially new species (referred to as "Rhinebothrium sp.") from U. granulatus (as Himantura granulata [Macleay]) collected from Heron Island, Queensland, Australia. Subsequently, Schaeffner and Beveridge (2012) reported the trypanorhynch Prochristianella clarkeae Beveridge, 1990 from U. granulatus (as H. granulata), also from Queensland. Onchoproteocephalidean and lecanicephalidean cestode records are conspicuously absent, as are records from outside of Australia.

As part of a global survey of elasmobranch-hosted cestodes, ten specimens of the mangrove whipray were collected from the Solomon Islands and northern Australia between 1997 and 2012 and examined for cestodes. The rays were found to host two new species of lecanicephalidean cestodes exhibiting a conspicuous, multi-partite apical structure comparable in complexity only to the apical structure of Seussapex Jensen et Russell, 2014 (see Jensen and Russell 2014). The two new species are consistent in scolex morphology and proglottid anatomy with the tax- on referred to by Jensen et al. (2016) as "New Genus 12." A new genus is erected herein to house the two new species from U. granulatus and "New Genus 12 n. sp. 1" of Jensen et al. (2016). This is the first record of lecanicephalidean tapeworms from U. granulatus, and the third report of lecanicephalideans from the Solomon Islands (see also Cielocha et al. 2013, Jensen et al. 2016).

\section{MATERIALS AND METHODS}

Host specimens examined consisted of ten individuals of the mangrove whipray, Urogymnus granulatus, from the Solomon Islands and northern Australia. Eight specimens were collected from near Rarumana $\left(08^{\circ} 13^{\prime} 24^{\prime \prime} \mathrm{S} ; 157^{\circ} 00^{\prime} 02^{\prime \prime} \mathrm{E}\right)$, off the island of Vonavona, Western Province, Solomon Islands between 19-23 March 2012 (host specimens nos. SO-9, SO-17-19, SO-21, SO23-25). Two specimens were collected from Australia: one specimen from Darwin (12²0'11"S; 130 54'39"E), Northern Territory on 6 August 1997 (host specimen no. AU-32) and one specimen from Weipa (12³5'11"S; 141 42'34"E), Queensland on 16 May 2004 (host specimen no. CM03-74). Additional host data are given in Table 1. Rays were captured using a gill net or hand spear. The body cavity of each ray was opened with a mid-ventral incision, and the spiral intestine was removed and opened with a longitudinal incision. Select worms were removed and fixed in $95 \%$ 
ethanol for future molecular analysis. The remaining worms and the spiral intestine were fixed in $10 \%$ seawater-buffered formalin and eventually transferred to $70 \%$ ethanol for permanent storage. Tapeworm specimens of the new genus were found parasitising eight of the ten host specimens examined (see Table 1).

Formalin-fixed specimens were prepared as whole mounts for light microscopy as follows. Worms were hydrated, stained in Delafield's hematoxylin, differentiated in tap water, destained in $70 \%$ acidic ethanol, alkanised in $70 \%$ basic ethanol, dehydrated in a graded ethanol series, cleared in methyl salicylate, and mounted on glass slides under cover slips in Canada balsam.

Specimens for scanning electron microscopy (SEM) were prepared as follows. They were hydrated, transferred to $1 \%$ osmium tetroxide $\left(\mathrm{OsO}_{4}\right)$ and refrigerated at $4{ }^{\circ} \mathrm{C}$ overnight, rinsed in distilled water, dehydrated in a graded ethanol series, and transferred to hexamethyldisilizane (HMDS) (Ted Pella, Inc., Redding, California, USA) for $30 \mathrm{~min}$. Worms were then allowed to air-dry before being mounted on aluminum stubs on double-sided adhesive carbon tape. Specimens were sputter-coated with $\sim 35 \mathrm{~nm}$ of gold/palladium and examined with an FEI Versa 3D Dual Beam (FEI, Hillsboro, Oregon, USA) scanning electron microscope at the Microscopy and Analytical Imaging Laboratory, University of Kansas, Lawrence, Kansas, USA.

Histological sections of two terminal proglottids ( 1 terminal proglottid of each of the 2 new species) were prepared as follows. Terminal proglottids were removed and the scolex and remaining strobila were saved and prepared as a permanent whole-mounted voucher. Terminal proglottids were dehydrated in a graded ethanol series, cleared in xylene and embedded in paraffin following conventional protocols. Serial sections were cut at $7 \mu \mathrm{m}$ intervals using an Olympus TBS CUT 4060 microtome (Triangle Biomedical Sciences, Durham, North Carolina, USA). Sections were attached to glass slides by floating on 3\% sodium silicate solution, and allowed to air-dry on a slide warmer. Sections were deparaffinised in xylene, hydrated, stained with hematoxylin, counterstained in eosin, differentiated in Scott's solution, dehydrated in a graded ethanol series, and cleared in xylene. Sections were then mounted under cover slips in Canada balsam.

Histological sections of scoleces of each species were prepared as follows. Scoleces were removed, and the strobila was prepared as a whole-mounted voucher. Scoleces were dehydrated in a graded ethanol series, transferred to a $1: 1$ solution of $100 \%$ ethanol and Technovit ${ }^{\mathbb{R}} \mathrm{H} 7100$ infiltrating resin (Heraeus Kluzer $\mathrm{GmbH}$, Wehrheim, Germany) for two hours, then transferred to pure infiltrating resin and refrigerated at $4{ }^{\circ} \mathrm{C}$ overnight. Scoleces were then embedded in Technovit ${ }^{\mathbb{R}} \mathrm{H} 7100$ embedding solution in plastic block holders. Serial sections were cut at $4 \mu \mathrm{m}$ intervals with a glass knife using an Olympus TBS CUT 4060 microtome. Sections were attached to Fisherbrand ${ }^{\circledR}$ Superfrost Plus charged microscope slides (Fisherbrand; Fisher, Pittsburgh, Pennsylvania, USA) by floating on $\sim 10 \mu 1$ drops of distilled water, and allowed to air-dry. Sections were stained with hematoxylin, counterstained in eosin, differentiated in Scott's solution, dehydrated in a graded ethanol series, dried for $\sim 2 \min$ in a $15^{\circ} \mathrm{C}$ oven, and then mounted under cover slips in Canada balsam. Strobila vouchers of specimens for which scoleces were prepared for SEM or sectioned, and scolex vouchers of specimens for which mature proglottids were sectioned, were prepared as whole mounts following methods described above.
Table 1. Juvenile and mature specimens of Urogymnus granulatus (Macleay) examined for Corollapex gen. $\mathrm{n}$. with their disk width measurements, sex and regional collection locality.*

\begin{tabular}{|c|c|c|c|c|c|c|}
\hline Maturity & $\begin{array}{l}\text { Collection } \\
\text { locality }\end{array}$ & $\begin{array}{l}\text { Host } \\
\text { specimen } \\
\text { number }\end{array}$ & $\begin{array}{l}\text { Disk } \\
\text { width } \\
(\mathrm{cm})\end{array}$ & Sex & $\begin{array}{l}\text { C. cairae } \\
\text { gen. n. et } \\
\text { sp. n. }\end{array}$ & $\begin{array}{l}\text { C. tingoi } \\
\text { gen. n. et } \\
\text { sp. n. }\end{array}$ \\
\hline \multirow{6}{*}{ Juvenile } & \multirow{4}{*}{$\begin{array}{l}\text { Western } \\
\text { Province, } \\
\text { Solomon } \\
\text { Islands }\end{array}$} & SO-21 & 34 & $\mathrm{~F}$ & $\checkmark$ & - \\
\hline & & $\mathrm{SO}-23$ & 33 & $\mathrm{~F}$ & $\checkmark$ & $\checkmark$ \\
\hline & & SO-24 & 34 & M & $\checkmark$ & - \\
\hline & & SO-25 & 33 & $\mathrm{~F}$ & - & - \\
\hline & Qld., Australia & CM03-74 & 34 & M & $\checkmark$ & - \\
\hline & N.T., Australia & AU-32 & 32 & M & - & - \\
\hline \multirow{4}{*}{ Mature } & \multirow{4}{*}{$\begin{array}{l}\text { Western } \\
\text { Province, } \\
\text { Solomon } \\
\text { Islands }\end{array}$} & SO-9 & 105 & $\mathrm{~F}$ & - & $\checkmark$ \\
\hline & & SO-17 & 103 & M & - & $\checkmark$ \\
\hline & & SO-18 & 108 & M & - & $\checkmark$ \\
\hline & & SO-19 & 115.5 & $\mathrm{~F}$ & - & $\checkmark$ \\
\hline
\end{tabular}

*see http://tapewormdb.uconn.edu for additional host specimen information. F - female; M - male; Qld. - Queensland; N.T. - Northern Territory.

Line drawings were made using a camera lucida attached to a Zeiss Axioskop 2 Plus (Carl Zeiss Microscopy, LLC, Thornwood, New York, USA). Photomicrographs of whole mounts and histological sections were obtained with a Leica DFC420 (Leica Microsystems Inc., Buffalo Grove, Illinois, USA), a Leica DFC480 or a Lumenera Infinity 3 (Lumenera Corporation, Ottawa, Ontario, Canada) attached to a Zeiss Axioskop 2 Plus. Measurements were made using Openlab Demo Version 4.0.4 or the Leica Application Suite V3 (Leica Microsystems) image analysis software programs. Measurements are reported in micrometres unless otherwise specified and are given as ranges followed in parentheses by the mean, standard deviation, number of individuals measured, and total number of measurements made if more than one measurement was taken for each individual. Measurements of reproductive organs are made from terminal mature proglottids only. Microthrix terminology follows Chervy (2009). Elasmobranch higher classification follows Naylor et al. (2012a); dasyatid classification follows Last et al. (2016b). Museum abbreviations used are as follows: Institute of Parasitology (IPCAS), Biology Centre, Czech Academy of Sciences, České Budějovice, Czech Republic; Lawrence R. Penner Parasitology Collection (LRP), University of Connecticut, Storrs, Connecticut, USA; Queensland Museum (QM), South Brisbane, Queensland, Australia; National Museum of Natural History (USNM), Smithsonian Institution, Washington, D.C., USA.

\section{RESULTS}

\section{Corollapex gen. n.}

ZooBank number for species: urn:1sid:zoobank.org:act:2FEFB6C7-5425-4929-A8D3-5F300C00CDE2

Diagnosis. Worms euapolytic. Scolex with scolex proper, four acetabula and apical structure consisting of apical modification of scolex proper (AMSP) and apical organ. Acetabula in form of suckers. Apical modification of scolex proper cylindrical, housing apical organ; posterior portion with conspicuous hastate spinitriches, anterior rim invaginable; anterior portion devoid of 
hastate spinitriches, invaginable. Apical organ with external and internal components; external component in form of central disk surrounded by eight concave muscular, membrane-bound pads, retractable, non-invaginable; central disk with opening to internal component; internal component glandular, heterogeneous.

Cephalic peduncle absent. Proglottids slightly craspedote, non-laciniate; immature proglottids not laterally expanded; conspicuous, circumcortical longitudinal muscle bundles absent. Testes four, arranged in single medial column, one layer deep in cross-section, in single field anterior to ovary. Vas deferens sinuous, extending from level posterior to ovary to posterior margin of anterior-most testis, expanded to form external seminal vesicle. Cirrus sac pyriform, angled anteriorly, containing cirrus. Cirrus armed, thin-walled. Internal seminal vesicle present. Genital pores lateral, irregularly alternating; genital atrium shallow.

Ovary H-shaped in dorsoventral view, tetralobed in cross-section, compact. Vagina medial, thin-walled, sinuous, extending from ootype region to cirrus sac, opening into genital atrium posterior to cirrus sac. Seminal receptacle absent. Vitellarium follicular; vitelline follicles large, in two lateral bands; each band consisting of one dorsal and one ventral column, extending almost entire length of proglottid, partially interrupted by ovary; follicles (with few exceptions) absent anterior to cirrus sac on poral side. Uterus saccate, mostly medial, extending from anterior margin of ovary to posterior margin of anterior-most testis. Eggs not observed. Excretory vessels in two lateral pairs. Parasites of Dasyatidae (Myliobatiformes). Indo-West Pacific region.

Type species: Corollapex cairae sp. n.

Additional species: Corollapex tingoi sp. n.; Corollapex sp. n. 1 (as "New Genus 12 n. sp. 1" in Jensen et al. [2016])

E ty m o logy: Corolla, Latin, feminine, diminutive of corona; crown, wreath, halo, rim, border. This genus is named for the unique shape of the external component of its apical organ, which resembles a whorl of flower petals.

Remarks. The phylogenetic analysis of Jensen et al. (2016) based on molecular sequence data placed a specimen consistent with the generic diagnosis of Corollapex gen. n. (referred to therein as "New Genus 12 n. sp. 1") robustly within the Polypocephalidae. Morphological data support this placement, including the possession of a single column of four testes, two pairs of excretory vessels, vitelline follicles largely interrupted by the ovary, and an elaborate apical structure. Corollapex is easily distinguished from all 24 valid lecanicephalidean genera (see Jensen et al. 2016) by its unique apical structure morphology: an extensive cylindrical apical modification of the scolex proper (AMSP) and an apical organ with an external, retractable component consisting of a central disk surrounded by eight concave muscular, membrane-bound pads and an internal glandular component.

Specifically, Corollapex can be distinguished from the other genera in the Polypocephalidae as follows. While Polypocephalus Braun, 1878 and Anthemobothrium Shipley et Hornell, 1906 possess an apical organ divided into tentacles and Flapocephalus Deshmukh, 1979 an apical organ in the form of two muscular semi-circles, the apical organ of Corollapex is in the form of a central disk surrounded by eight concave muscular, membrane-bound pads. Corollapex differs from Anteropora Subhapradha 1955 (with the exception of A. comicus [Jensen, Nikolov et Caira, 2011]) and Hornellobothrium Shipley et Hornell, 1906 in possessing a scolex with acetabula in the form of suckers rather than bothridia. However, while A. comicus is hyperapolytic and possesses an AMSP that is highly elongate, Corollapex is apolytic and possesses an AMSP that is not highly elongate. Additionally, unlike Hornellobothrium, Corollapex does not possess laterally expanded proglottids in the anterior region of its strobila.

Corollapex most closely resembles Seussapex in its relatively large overall body size, and its possession of four acetabula in the form of suckers and a large, retractable, multipartite apical structure. However, they can be distinguished from one another in that the apical organ of Seussapex is externally bipartite (knob-like anterior and dome-shaped posterior parts, each independently retractable) housing two glandular compartments internally, while the apical organ of Corollapex is externally a single unit in the form of a central disk surrounded by eight concave muscular, membrane-bound pads, housing a single, albeit heterogeneous, compartment internally.

Following Jensen et al. (2016), three lecanicephalidean genera (Corrugatocephalum Caira, Jensen et Yamane, 1997, Healyum Jensen, 2001 and Quadcuspibothrium Jensen, 2001) remain incertae sedis. Its prominent apical organ easily distinguishes Corollapex from Healyum and Quadcuspibothrium, both of which possess a small, internal apical organ, and from Corrugatocephalum, which possesses an apical organ that is sucker-like with an internal corrugated surface. Corollapex is further distinguished from Quadcuspibothrium in having acetabula in the form of suckers rather than diamond-shaped bothridia. Corollapex can be distinguished from Corrugatocephalum and Quadcuspibothrium in its possession of testes in a single, rather than two or more layers. While Corollapex possesses a cirrus armed with spinitriches, the cirrus of Healyum lacks spinitriches (i.e. is unarmed).

\section{Corollapex cairae sp. n.}

Figs. 1, 2, 5A-C

ZooBank number for species:

urn:1sid:zoobank.org:act:A60B364B-3BF7-473D-B2BE-009BF770B02C

Description (based on whole mounts of ten complete mature and one incomplete mature worms, cross-sections of one mature proglottid, frontal sections of two scoleces, and one scolex prepared for SEM and its strobilar voucher). Worms euapolytic, 3.8-9.2 mm (6.8 $\pm 2 \mathrm{~mm}$; 10) long; maximum width at level of scolex; proglottids 47-93 $(68 \pm 17 ; 11)$ in number. Scolex (Figs. 1A, 2A) 308-527 (432 $\pm 74 ; 11)$ long by $211-295(241 \pm 32 ; 11)$ wide, consisting of 4 acetabula, apical modification of scolex proper, and apical organ. Acetabula in form of suckers, 47-71 $(61 \pm 6 ; 11 ; 46)$ in diameter. Apical modification of scolex 

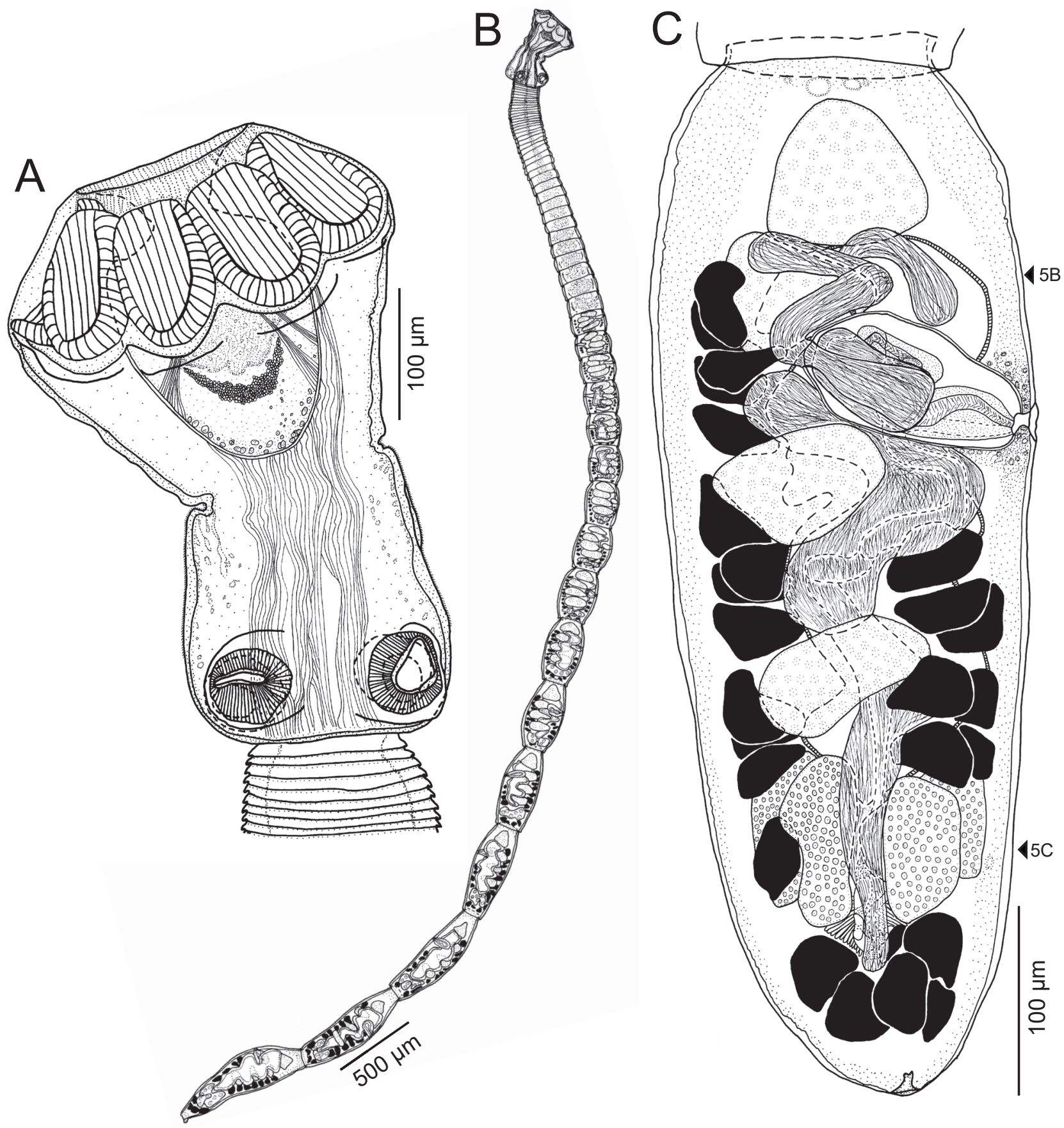

Fig. 1. Line drawings of Corollapex cairae gen. n. et sp. n. from Urogymnus granulatus (Macleay). A - whole worm (paratype, LRP 9126); B - scolex with protruded apical organ (holotype, QM G235510); C - mature terminal proglottid, dorsal view (holotype, QM G235510); arrowheads indicate level at which sections in Fig. 5B,C were taken.

proper (AMSP) cylindrical, housing apical organ; anterior portion and anterior rim of posterior portion invaginable. Apical organ with external and internal components; external component in form of central disk surrounded by 8 concave muscular, membrane-bound pads (Fig. 2I), $202-305(253 \pm 32 ; 10)$ long by $289-339(307 \pm 20 ; 8)$ wide when protruded, retractable, non-invaginable; central disk with opening to internal component (Fig. 2I); muscular pads $72-124(96 \pm 18 ; 8 ; 19)$ long by $73-102(85 \pm 9$; 9 ; 18) wide; internal component glandular, heterogeneous (Figs. 1A, 5A).
Scolex proper (Fig. 2F) with capiliform filitriches. Distal acetabular surface (Fig. 2H) with gladiate spinitriches and acicular filitriches. Posterior portion of AMSP (Fig. 2D) with large hastate spinitriches and capiliform filitriches; hastate spinitriches less dense toward posterior margin of posterior portion of AMSP (Fig. 2E). Anterior portion of AMSP (Fig. 2C) with acicular to capiliform filitriches. External component of apical organ (Fig. 2B) with acicular filitriches. Proglottids (Fig. 2G) with capiliform filitriches.

Cephalic peduncle absent. Proglottids slightly craspedote, non-laciniate. Immature proglottids 44-89 (64 \pm 16 ; 

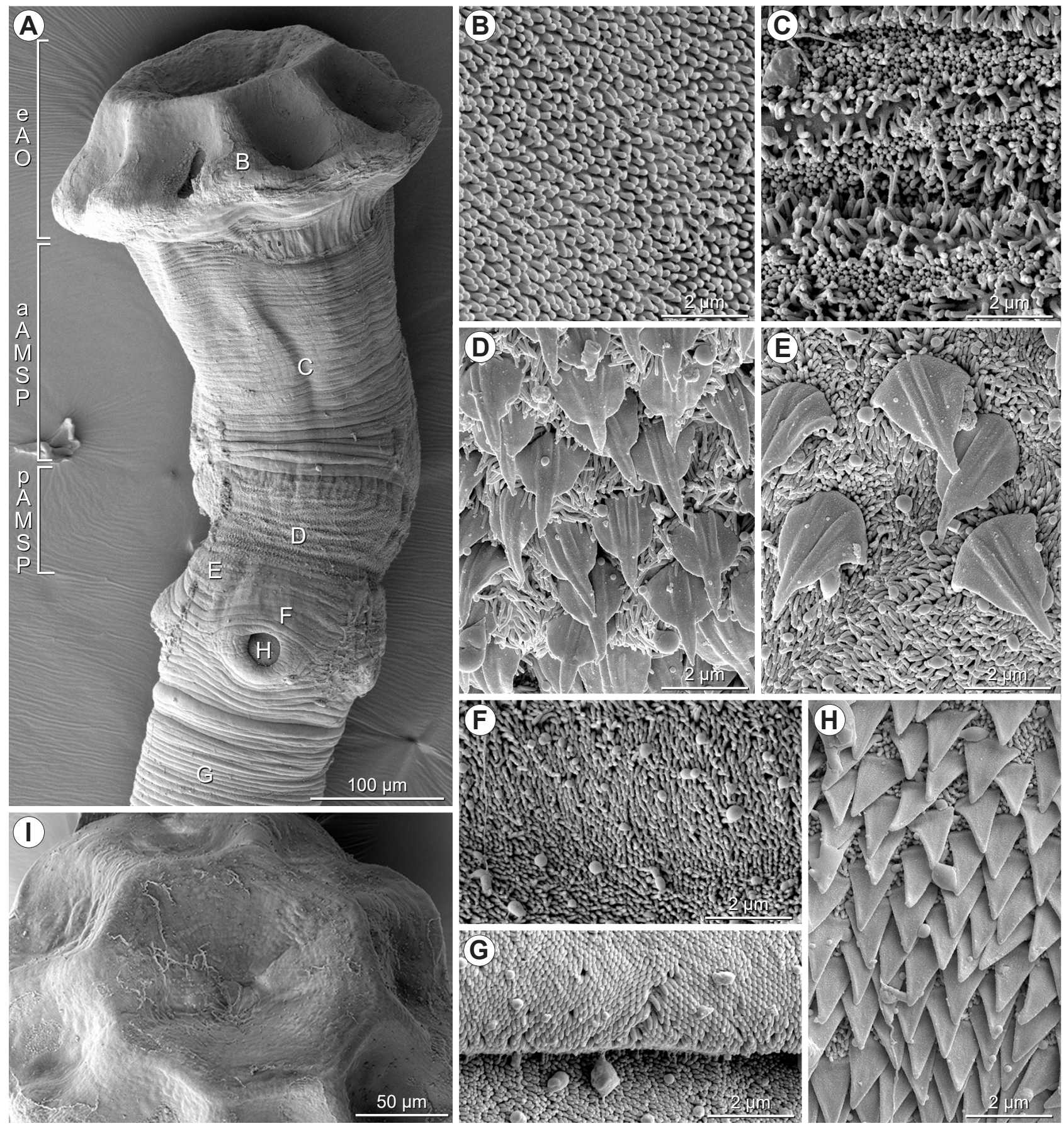

Fig. 2. Scanning electron micrographs of Corollapex cairae gen. n. et sp. n. from Urogymnus granulatus (Macleay). A - scolex with protruded apical organ (AO); small letters indicate location of details shown in Fig. 2B-H; B - acicular filitriches on external component of AO; C - acicular to capiliform filitriches on anterior portion of apical modification of scolex proper (AMSP); D - hastate spinitriches and capiliform filitriches on posterior portion of AMSP; $\mathbf{E}$ - sparse hastate spinitriches and capiliform filitriches on posterior margin of posterior portion of AMSP transitioning to scolex proper (SP); $\mathbf{F}$ - capiliform filitriches on SP; $\mathbf{G}$ - capiliform filitriches on proglottid; $\mathbf{H}$ - gladiate spinitriches and acicular filitriches on distal acetabular surface; $\mathbf{I}$ - central disk of external component of AO. Abbreviations: aAMSP - anterior portion of apical modification of scolex proper; eAO - external component of apical organ; pAMSP - posterior portion of apical modification of scolex proper.

11) in number, initially wider than long, becoming longer than wide with maturity; posterior-most immature proglottid 278-535 (393 $\pm 91 ; 12)$ long by $146-237(196 \pm 31 ; 12)$ wide. Mature proglottids $1-7(4 \pm 2 ; 11)$ in number, first mature proglottid $336-618(470 \pm 95 ; 12)$ long by $171-256$ (217 \pm 27 ; 12) wide, terminal proglottid 400-1,857 $(911 \pm 400 ; 11)$ long by $146-260(198 \pm 35 ; 11)$ wide.
Testes 4 in number, 36-102 $(60 \pm 14 ; 11 ; 31)$ long by $29-157(85 \pm 31 ; 10 ; 27)$ wide, arranged in single medial column, 1 row deep in cross-section (Fig. 5B), in field from near anterior margin of proglottid to near anterior margin of ovary. Vasa efferentia not observed. Vas deferens sinuous, extending from level posterior to ovary to posterior margin of anterior-most testis, expanded to form external 
seminal vesicle in mature proglottids. Cirrus sac pyriform, angled slightly anteriorly, 75-124 (100 $\pm 20 ; 8)$ long by $37-114(74 \pm 22 ; 10)$ wide, containing coiled cirrus. Cirrus armed with spinitriches, thin-walled. Internal seminal vesicle present. Genital pores lateral, irregularly alternating, $56-74 \%(66 \pm 6 ; 11)$ of proglottid length from posterior margin; genital atrium shallow.

Ovary H-shaped in dorsoventral view, tetralobed in cross-section (Fig. 5C), 33-233 (139 \pm 60 ; 9) long by 82-141 (116 $\pm 22 ; 7)$ wide, compact; ovarian bridge at center of ovary. Mehlis' gland near posterior margin of ovary. Vagina medial, thin-walled, sinuous, extending from ootype to genital atrium, opening into genital atrium posterior to cirrus sac. Seminal receptacle absent. Vitellarium follicular; vitelline follicles medullary, large, 14-108 $(50 \pm 22 ; 11 ; 33)$ long by $19-61(39 \pm 11 ; 10 ; 30)$ wide, in 2 lateral bands; each band consisting of 1 dorsal and 1 ventral column (Fig. 5B), extending from posterior margin of proglottid to level posterior to genital pore (individual follicles in few specimens anterior to genital pore) on poral side and to level of posterior margin of anterior-most testis on aporal side, partially interrupted by ovary. Uterus saccate, mostly medial, extending from slightly posterior to anterior margin of ovary to level of anterior-most testis, laterally displaced in mature proglottids (Fig. 1A). Eggs not observed. Excretory vessels in 2 lateral pairs.

Type and only host: Urogymnus granulatus (Macleay), the mangrove whipray (Myliobatiformes: Dasyatidae).

Typ e 1 o cality: Near Rarumana $\left(08^{\circ} 13{ }^{\prime} 24^{\prime \prime S} ; 157^{\circ} 00^{\prime} 02^{\prime \prime E}\right)$, Vonavona Island, Western Province, Solomon Islands, Solomon Sea (host specimen nos. SO-23 and SO-24).

Additional localities: Near Rarumana $\left(08^{\circ} 14^{\prime} 13^{\prime \prime}\right.$; $\left.157^{\circ} 01^{\prime} 54^{\prime \prime E}\right)$, Vonavona Island, Western Province, Solomon Islands, Solomon Sea (host specimen no. SO-21); Weipa (02 ${ }^{\circ} 35^{\prime} 11^{\prime \prime S}$; 141 $\left.{ }^{\circ} 42^{\prime} 34^{\prime \prime E}\right)$, Queensland, Australia, Gulf of Carpentaria (host specimen no. CM03-74).

Site of infection: Spiral intestine.

Prevalence of infection: 40\% (4 of 10 host specimens).

Type material: Holotype (QM No. G235510), five paratypes (QM Nos. G235511-G235515; 3 whole mounts, 1 proglottid cross-section series and its whole-mounted voucher, and 1 scolex frontal section series stained with hematoxylin and its whole-mounted voucher); three paratypes (USNM Nos. 1422068-1422070; all whole mounts;), five paratypes (LRP Nos. 9162-9177; 3 whole mounts, 1 SEM voucher, and 1 scolex frontal section series stained with PAS and its whole-mounted voucher); one paratype (IPCAS No. C-743; whole mount); scolex prepared for SEM retained in the collection of $\mathrm{KJ}$ at the University of Kansas.

Additional material: Nine immature or incomplete voucher specimens ( 7 whole mounts, and 2 scoleces prepared for SEM and their whole-mounted vouchers) retained in the personal collection of $\mathrm{KJ}$ at the University of Kansas.

Etymology: This species is named in honour of Janine N. Caira for her extensive, major contributions to and boundless support of lecanicephalidean biodiversity research.

Remarks. While most lecanicephalideans, particularly polypocephalids, are small, some less than $1 \mathrm{~mm}$ in total length (see Caira and Jensen 2014), this new species is somewhat unusual in reaching total lengths of up to $9.2 \mathrm{~mm}$. It is also of note that the apical organ of all specimens of this new species recovered was fully or mostly protruded. All 15 type specimens and 9 voucher specimens examined in this study parasitised juvenile host specimens less than $34 \mathrm{~cm}$ in disk width (see Table 1).

\section{Corollapex tingoi sp. n.}

Figs. 3, 4, 5D-G

ZooBank number for species:

urn:1sid:zoobank.org:act:CFC0BC23-FD93-4975-BA94-39D9F861F560

Description (based on whole mounts of 14 complete mature worms, cross-sections of one mature proglottid, frontal sections of two scoleces, and two whole worms and one scolex prepared for SEM). Worms euapolytic, 1.1-3.3 mm (2 $\pm 1 \mathrm{~mm}$; 14) long; maximum width 205-296 $(244 \pm 28 ; 14)$ at level of scolex; proglottids $14-30(20 \pm 5$; $14)$ in number. Scolex $385(\mathrm{n}=1)$ long when apical organ everted (Fig. 5G), 238-336 (296 \pm 25 ; 13) long when apical organ retracted (Figs. 3B, 4A), consisting of 4 acetabula, apical modification of scolex proper, and apical organ. Acetabula in form of suckers, $51-72(60 \pm 5 ; 14 ; 58)$ in diameter. Apical modification of scolex proper (AMSP) cylindrical, housing apical organ; anterior portion and anterior rim of posterior portion invaginable. Apical organ with external and internal components; external component in form of central disk surrounded by 8 concave muscular, membrane-bound pads, 229 (1) long by 249 (1) wide when protruded, 182-283 $(232 \pm 27 ; 13)$ long by $160-243$ (201 \pm 27 ; 13) wide when retracted, non-invaginable; central disk with opening to internal component; muscular pads $51-74(64 \pm 6 ; 14 ; 27)$ long by $42-68(59 \pm 7 ; 14 ; 28)$ wide; internal component glandular, heterogeneous.

Scolex proper (Fig. 4D) with capiliform filitriches. Distal acetabular surface (Fig. 4E) with gladiate spinitriches and acicular filitriches. Posterior portion of AMSP (Fig. 4B) with large hastate spinitriches and acicular to capiliform filitriches. Anterior portion of AMSP and apical organ microtriches not observed. Proglottids (Fig. 4G) with capiliform filitriches.

Cephalic peduncle absent. Proglottids slightly craspedote, non-laciniate. Immature proglottids 13-27 (19 \pm 4; 14) in number, initially wider than long, becoming longer than wide with maturity; posterior-most immature proglottid 161-328 (229 $\pm 48 ; 14)$ long by $91-187$ (135 \pm 27 ; 14) wide. Mature proglottids $1-3(2 \pm 1 ; 14)$ in number, first mature proglottid 270-633 (434 \pm 133 ; 14) long by 110-190 $(148 \pm 21 ; 14)$ wide, terminal proglottid 375-890 ( $585 \pm 137$; 14) long by $118-195(147 \pm 21 ; 14)$ wide.

Testes 4 in number, $28-80(49 \pm 14 ; 14 ; 40)$ long by $32-107(71 \pm 16 ; 14 ; 40)$ wide, arranged in a single medial column, 1 row deep in cross-section, in field from near anterior margin of proglottid to near anterior margin of ovary. Vasa efferentia not observed. Vas deferens sinuous, extending from level posterior to ovary to posterior margin of anterior-most testis, expanded to form external seminal vesicle in terminal mature proglottids. Cirrus sac pyriform, 


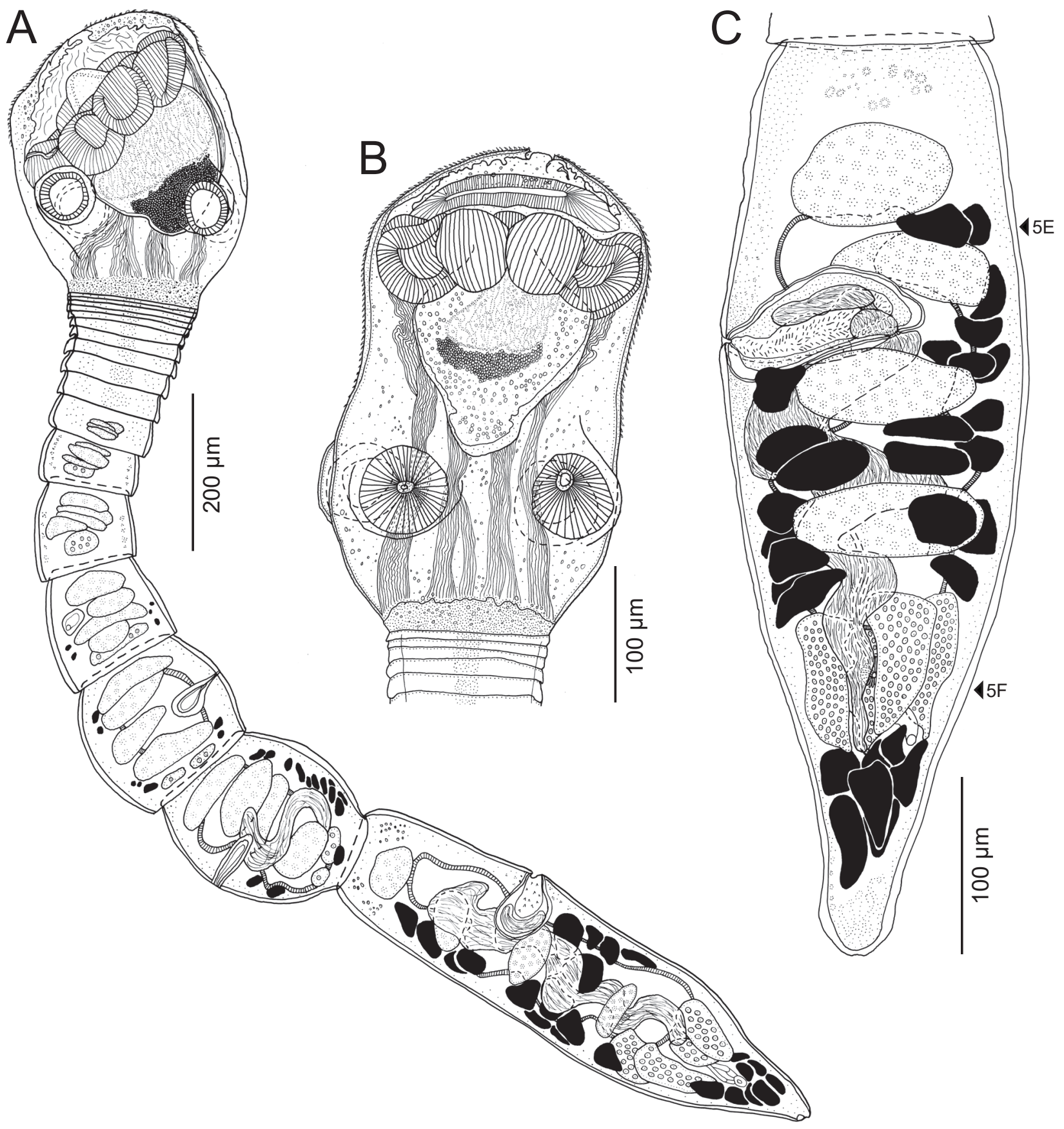

Fig. 3. Line drawings of Corollapex tingoi gen. n. et sp. n. from Urogymnus granulatus (Macleay). A - whole worm (holotype, QM G235516); B - scolex with retracted apical organ (paratype, QM G235517); C - mature terminal proglottid, dorsal view (paratype, LRP 9179); arrowheads indicate level at which sections in Fig. 5E,F were taken.

angled slightly anteriorly, $52-150(83 \pm 27 ; 13)$ long by $32-86(53 \pm 18 ; 13)$ wide, containing coiled cirrus. Cirrus armed with spinitriches, thin-walled. Internal seminal vesicle present. Genital pores lateral, irregularly alternating, $61-68 \%(65 \% \pm 2 ; 14)$ of proglottid length from posterior end; genital atrium shallow.

Ovary H-shaped in dorsoventral view, tetralobed in cross-section (Fig. 5F), 56-188 (101 \pm 43 ; 13) long by 52-127 (84 \pm 23 ; 14) wide, compact; ovarian bridge at center of ovary. Mehlis' gland near posterior margin of ovary. Vagina medial, thin-walled, sinuous, extending from ootype to genital atrium, opening into genital atrium posterior to level of cirrus sac. Seminal receptacle absent. Vitellarium follicular; vitelline follicles medullary, large, $8-59(32 \pm 13 ; 14 ; 42)$ long by $16-50(26 \pm 8 ; 14 ; 42)$ wide, in 2 lateral bands; each band consisting of 1 dorsal and 1 ventral column (Fig. 5E), extending from posterior margin of proglottid to level posterior to genital pore (individual follicles in few specimens anterior to genital pore) on poral side and to level of posterior margin of anterior-most testis on aporal side, partially interrupted by ovary. Uterus saccate, mostly medial, extending from slightly posterior 

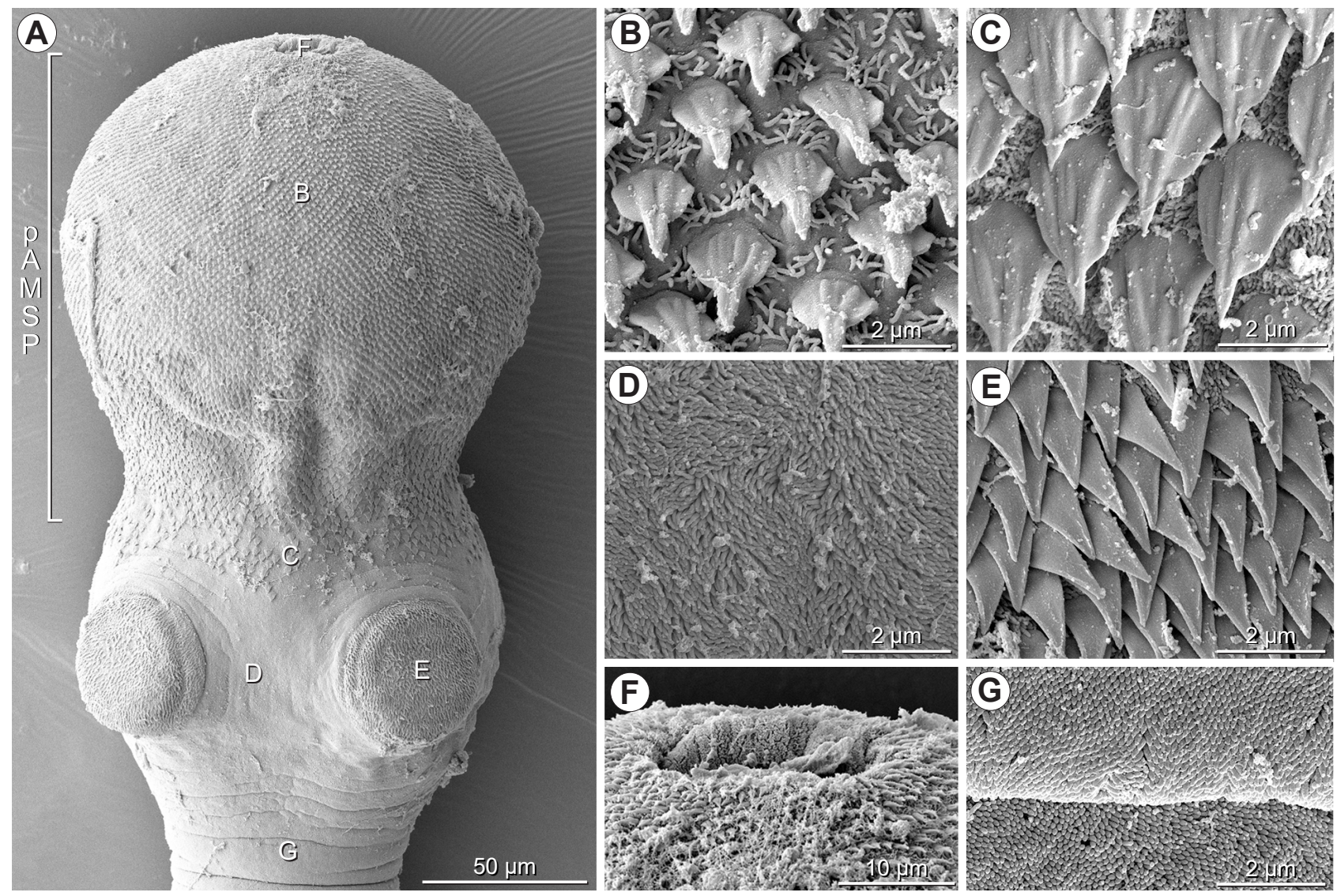

Fig. 4. Scanning electron micrographs of Corollapex tingoi gen. n., sp. n. from Urogymnus granulatus (Macleay). A - scolex with retracted apical organ; small letters indicate location of details shown in Fig. 5B-G; B - hastate spinitriches and acicular to capiliform filitriches on posterior portion of apical modification of scolex proper (AMSP); $\mathbf{C}$ - hastate spinitriches and acicular to capiliform filitriches on posterior margin of posterior portion of AMSP transitioning to scolex proper (SP); D - capiliform filitriches on SP; $\mathbf{E}$ - gladiate spinitriches and acicular filitriches on distal acetabular surface; $\mathbf{F}$ - aperture of AMSP; $\mathbf{G}$ - capiliform filitriches on proglottid. Abbreviations: pAMSP - posterior portion of apical modification of scolex proper.

to anterior margin of ovary to level of anterior-most testis, laterally displaced in mature proglottids. Eggs not observed. Excretory vessels in 2 lateral pairs

Type and only host: Urogymnus granulatus (Macleay), the mangrove whipray (Myliobatiformes: Dasyatidae).

Type 1 oc a lity: Near Rarumana $\left(08^{\circ} 13 ' 24^{\prime \prime S} ; 157^{\circ} 00^{\prime} 02^{\prime \prime E}\right)$, Vonavona Island, Western Province, Solomon Islands, Solomon Sea (host specimens nos. SO-9, SO-17, SO-18, SO-19 and $\mathrm{SO}-23$ ).

Site of infection: Spiral intestine.

Prevalence of infection: 50\% (5 of 10 host specimens).

Type material: Holotype (QM No. G235516), six paratypes (QM Nos. G235517-G235522; 4 whole mounts, 1 proglottid cross-section series and 1 scolex frontal section series stained with hematoxylin, and their whole-mounted vouchers); five paratypes (USNM Nos. 1422071-1422075; all whole mounts); four paratypes (LRP Nos. 9178-9186; 3 whole mounts and 1 scolex frontal section series stained with hematoxylin and its whole-mounted voucher); one paratype (IPCAS No. C-744; whole mount); one scolex prepared for SEM and its whole-mounted voucher, and two whole worms prepared for SEM retained in the collection of KJ at the University of Kansas.
Additional material: Eleven whole-mounted immature voucher specimens retained in the personal collection of $\mathrm{KJ}$ at the University of Kansas.

Etymology: This species is named for Tingo Leve, WWF Solomon Islands, for his facilitation of and logistical support for collections in the Solomon Islands.

Remarks. This new species, though very similar in overall scolex morphology and proglottid anatomy to Corollapex cairae, can be distinguished from the latter species in that it possesses fewer proglottids overall (14-30 vs 47-93, respectively), but only slightly fewer mature proglottids (on average 2 [1-3] vs 4 [1-7], respectively). Additionally, while the first mature proglottid in Corollapex tingoi sp. $\mathrm{n}$. is proglottid number 14-28, the first mature proglottid in C. cairae is proglottid number 45-90. Consequently, the two species also differ from one another in total length; while mature specimens of $C$. tingoi only reach a maximum total length of $3.3 \mathrm{~mm}$, those of $C$. cairae are $3.8-9.2 \mathrm{~mm}$ in total length.

All 15 type and 9 voucher specimens of the large species, C. cairae, were found exclusively parasitising juvenile host individuals less than $34 \mathrm{~cm}$ in disk width, while 

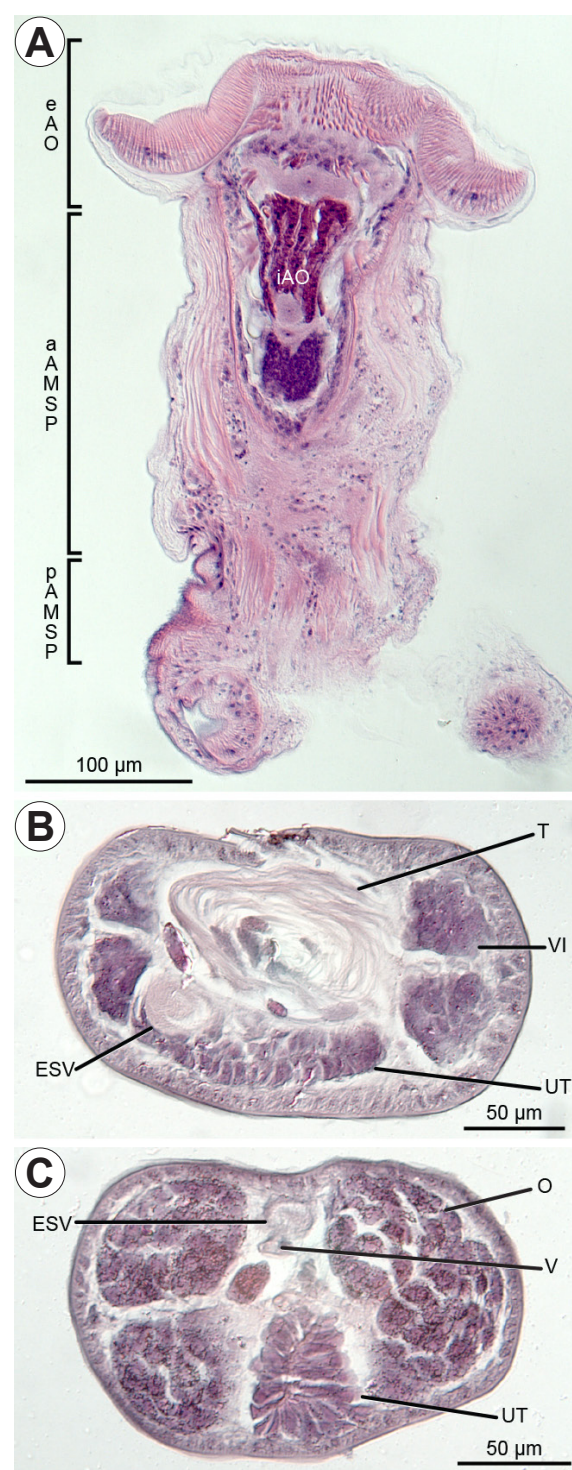
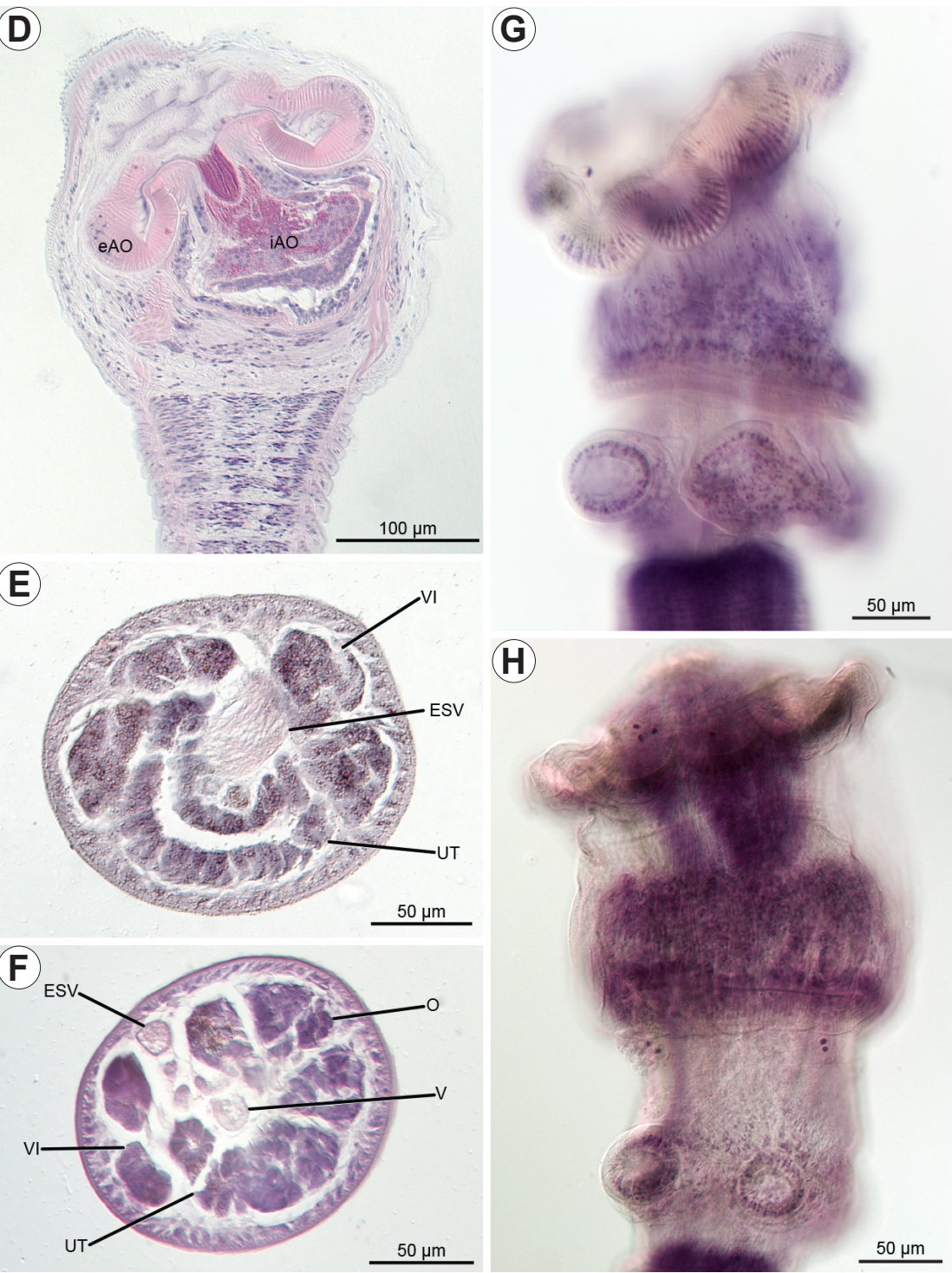

Fig. 5. Photomicrographs of species of Corollapex gen. n. A-C - Corollapex cairae gen. n. et sp. n. from Urogymnus granulatus (Macleay); A - frontal section of scolex with protruded apical organ; $\mathbf{B}$ - cross section of mature proglottid anterior to cirrus sac; $\mathbf{C}$ - cross section of mature proglottid slightly posterior to ovarian bridge; D-G - Corollapex tingoi gen. n. et sp. n. from Urogymnus granulatus (Macleay); D - frontal section of scolex with retracted apical organ; $\mathbf{E}$ - cross section of mature proglottid anterior to cirrus sac; $\mathbf{F}$ - cross section of mature proglottid slightly posterior to ovarian bridge; $\mathbf{G}$ - scolex with protruded apical organ; $\mathbf{H}$ - scolex of Corollapex sp. n. 1 (as "New Genus 12 n. sp. 1" of Jensen et al. 2016) from Maculabatis gerrardi (Gray) (LRP No. 8790) with protruded apical organ. Abbreviations: aAMSP - anterior region of apical modification of scolex proper; eAO - external component of apical organ; ESV - external seminal vesicle; iAO - internal component of apical organ; O - ovary; pAMSP - posterior region of apical modification of scolex proper; T - testis; UT - uterus; V - vagina; VI - vitelline follicle.

18 type and 11 voucher specimens of the small species, C. tingoi sp. n., were found parasitising mature host individuals greater than $100 \mathrm{~cm}$ in disk width; only two specimens of Corollapex tingoi were found parasitising a single juvenile ray smaller than $34 \mathrm{~cm}$ in disk width. Thus, despite all but two of the ten rays having been collected from essentially the same locality within one to four days of one another, the two cestode congeners co-occurred in only a single, small ray (see Table 1).

All but one of the individual worms of Corollapex tingoi examined herein presented with their apical organs fully or mostly retracted. Thus, scolex length with the apical organ protruded could only be measured for a single specimen.
Corollapex sp. n. 1 of Jensen et al. (2016)

Fig. $5 \mathrm{H}$

Synonyms: New Genus 12 n. sp. 1 of Jensen et al. (2016)

Host species: Maculabatis gerrardi (Gray) (as $H$. cf. gerrardi 2 of Naylor et al. [2012b] in Jensen et al. 2016), whitespotted whipray (Myliobatiformes: Dasyatidae).

L o c a 1 it y : Sidu $\left(01^{\circ} 21^{\prime} 45^{\prime \prime S}\right.$; $\left.110^{\circ} 04^{\prime} 10^{\prime \prime E}\right)$, West Kalimantan, Borneo, Java Sea (host specimen no. KA-211).

Site of infection: Spiral intestine.

Specimens examined: LRP No. 8790 (hologenophore). 


\section{DISCUSSION}

In the recent phylogenetic analysis by Jensen et al. (2016) based on molecular sequence data, Corollapex, represented by Corollapex sp. n. 1 (referred to therein as "New Genus 12 n. sp. 1") from Maculabatis gerrardi (Gray) (as Himantura cf. gerrardi 2 of Naylor et al. 2012b), placed robustly within the Polypocephalidae. In fact, its proglottid anatomy (i.e. the possession of a single column of four testes, two pairs of excretory vessels and vitelline follicles largely interrupted by the ovary) is essentially identical to that of other genera in the family (see fig. 3 of Jensen et al. 2016). While the shape of its apical organ is unique among polypocephalid genera, the complexity of the apical structure in general is most similar to that of Seussapex. Anterior to the scolex proper (SP) bearing four suckers, both genera possess a cylindrical apical modification of the scolex proper (AMSP) comprising distinct posterior (with hastate spinitriches) and anterior (without hastate spinitriches; not known for $C$. tingoi) portions, and an apical organ (AO). In both genera, at least the anterior portion of the AMSP is invaginable into the $\mathrm{SP}$ and the $\mathrm{AO}$ is retractable into the AMSP, and ultimately also into the SP. Internal AO morphology is also quite similar in both genera; they possess one or more large internal glandular compartment(s) associated with the external component of the AO.

However, the most conspicuous difference between Corollapex and Seussapex is in morphology of the external component of the AO. Whereas members of Seussapex have a bipartite AO (i.e. posterior retractable dome-shaped part and anterior retractable and/or invaginable knob-like part) that is not conspicuously muscular, the AO of members of Corollapex is not bipartite and is conspicuously muscular. In fact, the eight concave muscular, membrane-bound pads of Corollapex are entirely unlike the components of any described lecanicephalidean scolex to date. Each muscular pad appears to be controlled by a distinct internal muscle bundle that runs the entire length of the scolex, and presumably is responsible for retraction of this component of the AO into the SP.

Despite the similarity of apical organ complexity, representatives of Corollapex and Seussapex included in the phylogenetic analyses of Jensen et al. (2016) were not recovered as sister taxa. Instead, the representatives of Seussapex were recovered as sister to the two representatives of "New Genus 11" with high support, while the representative of Corollapex placed, albeit with low support, as sister taxon to a clade comprising members of Anteropora and Anthemobothrium.

With the description of Corollapex, the Lecanicephalidea now comprise 25 genera. Host associations of individual genera vary; for example, species of Anteropora collectively parasitize batoids of the torpediniform families Narkidae Fowler (Yamaguti 1934, Euzet 1994) and Narcinidae Gill (Subhapradha 1955, Jensen et al. 2011, Jensen et al. 2016), and the myliobatiform family Dasyatidae (see Mojica et al. 2013), and sharks of the orectolobiform family Hemiscylliidae Gill (see Jensen 2005). In contrast, species of Zanobatocestus Jensen, Mojica et Caira, 2014 parasitise Zanobatus schoenleinii (Müller et
Henle) (see Jensen et al. 2014), the sole species in the family Zanobatidae Fowler (Rhinopristiformes). Corollapex is one of 10 genera reported from dasyatid stingrays and one of only five genera that appear restricted to dasyatid hosts - the other four genera are Anthemobothrium, Flapocephalus, Seussapex and Tetragonocephlum Shipley et Hornell, 1905. To date, published records for Corollapex are restricted to Urogymnus granulatus, reported here, and Maculabatis gerrardi (Gray) (as H. cf. gerrardi 2 of Naylor et al. [2012b] in Jensen et al. 2016), as reported by Jensen et al. (2016).

Preliminary data suggest that at least six additional new species of Corollapex parasitise rays in the Indo-Pacific Ocean. In addition to parasitising U. granulatus and M. gerrardi, specimens consistent in morphology with the generic diagnosis of Corollapex were found parasitising a diversity of other species in the subfamily Urogymninae (i.e. Brevitrygon walga [Müller et Henle], Himantura cf. gerrardi 1 of Naylor et al. [2012b] [now a member of Maculabatis], Pateobatis uarnacoides [Bleeker], Urogymnus lobistomus [Manjaji-Matsumoto et Last] and Urogymnus polylepis [Bleeker]), as well as a single species of Neotrygon Castelnau (i.e. $N$. orientale Last, White et Séret; Neotrygoninae), all from waters in or around Borneo. Unfortunately, more specimens are needed to formally describe any one of these additional species in the future.

Based on the locality data for the specimens of Corollapex described herein, the specimen included in Jensen et al. (2016), and the additional host records listed above, the geographic distribution of Corollapex is limited to the waters surrounding the Solomon Islands and Borneo (including the Kinabatangan River), and northern Australia. While the actual geographic distribution of the genus is likely to include additional regions in the Indo-West Pacific region, it is curious that despite sampling of dasyatid hosts of the same or additional species from, for example, Vietnam, Madagascar, the Red Sea and northeastern India, specimens of Corollapex have not been recovered from these regions. The absence from at least a subset of these regions is likely a sampling artifact.

The host specimens of $U$. granulatus available for this study fell into one of two size classes: four mature individuals with a disc width (DW) of greater than $100 \mathrm{~cm}$ and six juvenile individuals with a DW of less than $34 \mathrm{~cm}$ (see Table 1). As mentioned in the remarks sections, specimens of $C$. cairae and $C$. tingoi were not randomly distributed among these host individuals. All 24 type and voucher specimens of $C$. cairae examined were recovered from juvenile rays of a disk width less than $35 \mathrm{~cm}$ while 29 type and voucher specimens of $C$. tingoi were recovered from mature rays of a disk width greater than $100 \mathrm{~cm}$; only two specimens of $C$. tingoi co-occurred with specimens of $C$. cairae in a juvenile host and both specimens were recovered from the same host individual (see Table 1).

While there is some evidence in elasmobranch tapeworms to suggest that species composition within a single host species may change depending on host size (see Caira 1992; J.N. Caira, University of Connecticut, Connecticut, USA - unpubl. data in Caira and Euzet 2001; 
T. Mattis - pers. comm. in Caira 1990), to date, there are no data to suggest that conspecific host individuals of different sizes are differentially parasitised by conspecific worms of different sizes. Even if this were the case, there would be no reason to expect larger worms exclusively in smaller hosts and vice-versa, and there is no evidence to suggest that individual tapeworms decrease in size as their hosts grow and mature. Thus, separate species status for C. cairae and C. tingoi is warranted at this time.

The distributional pattern exhibited by these two species of Corollapex may be an artifact of the relatively limited number of hosts examined of each size class and that, in fact, both species equally parasitise specimens of U. granulatus of all size classes. Alternatively, there is evidence to suggest that differential host diet of juvenile and mature $U$. granulatus may play a role. For gape-limited predators like teleosts, diet is strongly impacted by size, with the potential for gape-limit to contribute to a diet shift during maturation (e.g. Okada and Taniguchi 1971, Hambright 1991, Mittelback and Persson 1998, Dörner and Wagner 2003, Huss et al. 2008, Byström et al. 2012). Such ontogenetic shifts in diet are particularly well documented within the Elasmobranchii (Hoffmayer and Parsons 2003, Bethea et al. 2006, Hussey et al. 2011, Newman et al. 2012, Shiffman et al. 2014), including batoids (Brickle et al. 2003, Farias et al. 2006, Dale et al. 2011, Navia et al. 2011, Espinoza et al. 2013, Šantić et al. 2013, Spath et al. 2013). Body size has been demonstrated to have such a significant impact on prey choice that a predatory individual will likely share a greater proportion of its diet with a similarly-sized individual of a different species than with a conspecific of a different size (Polis 1984, Bax 1998). Assuming then that individuals of $U$. granulatus may consume qualitatively different prey items dependent upon their size, the differential distribution of the large and small species of Corollapex between small and large host specimens, respectively, could be accounted for by each tapeworm species utilising a different species or type of intermediate or paratenic host.

Unfortunately, few data are available on the diet or feeding biology of $U$. granulatus and no data are available on intermediate or paratenic host use of species of Corollapex to corroborate this hypothesis of differential transmission. The stomach contents of three specimens of
U. granulatus of a disk width of greater than $78 \mathrm{~cm}$ were listed by Ishihara et al. (1993). The stomach of the largest, presumably mature, specimen (male, $97 \mathrm{~cm} \mathrm{DW}$ ) was said to contain "... a very large sipunculid, crushed fragments of a calappid crab, and the well-digested remains of three small fishes (mainly vertebral columns, but one fish intact enough to estimate SL at about $28 \mathrm{~mm}$ )," while the stomach contents of a slightly smaller male $(78.95 \mathrm{~cm} \mathrm{DW})$ and female (79.6 cm DW) was said to contain ".... labrid (probably Haliochoeres sp., $50 \mathrm{~mm} \mathrm{SL}$ ), Valenciennea sp. (70 $\mathrm{mm} \mathrm{SL}$ ), an unidentified small gobiid, two sipunculids (79-86 mm) and a small octopus" and "...two Siganus sp. (51-77 mm SL), one blenniid (54 mm SL), one pomacentrid (37 mm SL), and the head of a gobiid," respectively (Ishihara et al. 1993, p. 26). Stomach content data of juvenile $U$. granulatus of similar disk width to those specimens examined for this analysis (i.e. less than $35 \mathrm{~cm} \mathrm{DW}$ ) are not available for comparison. Once again, the need for further investigation into elasmobranch tapeworm life-cycles and the link between host ecology and tapeworm community composition is evident.

Acknowledgements. The authors are grateful to Janine Caira (University of Connecticut), Tingo Leve (WWF Solomon Islands) and local Gilbertese fishermen for host collections in the Solomon Islands, to Lyle Squire of Cairns Marine and his crew for the collection of the specimen from the Gulf of Carpentaria (CM03), and Richard Mounsey and Julie Lloyd, formerly of Darwin Fisheries, for collection of the specimen from the Timor Sea (AU). We thank Hannah Ralicki (University of Connecticut) for the generation of molecular sequence data for the purposes of host identification confirmation and Elizabeth Jockusch (University of Connecticut) for molecular data oversight. Janine Caira kindly provided the photomicrograph of the hologenophore of Corollapex n. sp. 1 (LRP No. 8790). Collections in Queensland, Australia were conducted under Queensland Fisheries Service permit PRM4632I and collections in the Solomon Islands were conducted under a collecting permit issued by the office of the Minister for Education and Human Resources Development of the Solomon Islands. This project was supported by the US National Science Foundation (NSF) PEET award no. 0118882, BS\&I award nos. 0103640, 0542846, and 0542941, Planetary Biodiversity Inventories (PBI) award Nos. 0818696 and 0818823 , and Phylogenetic Systematics award nos. 1457762 and 1457776.

\section{REFERENCES}

BAX N.J. 1998: The significance and prediction of predation in marine fisheries. ICES J. Mar. Sci. 55: 997-1030.

Bethea D.M., Carlson J.K., Buckel J.A., Satterwhite M. 2006: Ontogenetic and site-related trends in the diet of the Atlantic sharpnose shark Rhizoprionodon terraenovae from the northeast Gulf of Mexico. Bull. Mar. Sci. 78: 287-307.

Brickle P., Laptikhovsky V., Pompert J., Bishop A. 2003 Ontogenetic changes in the feeding habits and dietary overlap between three abundant rajid species on the Falkland Islands' shelf. J. Mar. Biol. Ass. 83: 1119-1125.

Byström P., Huss M., Persson L. 2012: Ontogenetic constraints and diet shifts in perch (Perca fluviatilis): mechanisms and consequences for intra-cohort cannibalism. Freshwater Biol. 57: $847-857$.
CAIRA J.N. 1990: Metazoan parasites as indicators of elasmobranch biology. In: H.L. Pratt Jr., S.H. Gruber and T. Taniuchi (Eds.), Elasmobranchs as Living Resources: Advances in the Biology, Ecology, Systematics, and the Status of the Fisheries, NOAA Technical Report 90: NOAA/National Marine Fisheries Service, Silver Springs, MD, pp. 71-96.

CAIRA J. 1992: Verification of multiple species of Pedibothrium in the Atlantic nurse shark with comments on the Australasian members of the genus. J. Parasitol. 78: 289-308.

Caira J., Euzet L. 2001: Age of association between the nurse shark, Ginglymostoma cirratum, and tapeworms of the genus Pedibothrium (Tetraphyllidea: Onchobothriidae): implications from geography. Biol. J. Linn. Soc. 72: 609-614.

CAira J.N., JenSEn K. 2014: A digest of elasmobranch tapeworms. J. Parasitol. 100: 373-391. 
Chervy L. 2009: Unified terminology for cestode microtriches: a proposal from the international workshops on cestode systematics in 2002-2008. Folia Parasitol. 56: 199-230.

Cielocha J.J., Yoneva A., Cantino M.E., Daniels S., Jensen K. 2013: Ultrastructure of the sperm of Adelobothrium sp. (Cestoda: Lecanicephalidea). Invertebr. Biol. 132: 315-325.

Dale J.J., Wallsgrove N.J., Popp B.N., Holland K.N. 2011: Nursery habitat use and foraging ecology of the brown stingray Dasyatis lata determined from stomach contents, bulk and amino acid stable isotopes. Mar. Ecol. Prog. Ser. 433: 221-236.

Dörner H., WaGner A. 2003: Size-dependent predator-prey relationships between between perch and their fish prey. J. Fish Biol. 62: $1020-1032$

Espinoza M., Clarke T.M., Villalobos-Rojas F., WehrtMANN I.S. 2013: Diet composition and diel feeding behavior of the banded guitarfish, Zapteryx xyster along the Pacific coast of Coasta Rica, Central America. J. Fish Biol. 82: 286-305.

Euzet L. 1994: Order Lecanicephalidea Wardle \& McLeod, 1952. In: L.F. Khalil, A. Jones and R.A. Bray (Eds.), Keys to the Cestode Parasites of Vertebrates: CAB International, Wallingford, pp. 339-351.

Farias I., Figueiredo I., Moura T., Gordo L.S., Neves A., Serra-Pereira B. 2006: Diet comparison of four ray species (Raja clavata, Raja brachyura, Raja montagui and Leucoraja naevus) caught along the Portuguese continental shelf. Aquat. Living Resour. 19: 105-114.

HAMBRIGHT K.D. 1991: Experimental analysis of prey selection by largemouth bass: role of predator mouth width and prey body. Trans. Am. Fish. Soc. 120: 500-508.

Hoffmayer E.R., Parsons G.R. 2003: Food habits of three shark species from the Mississippi Sound in the Northern Gulf of Mexico. Southeast. Nat. 2: 271-280.

Huss M., Byström P., Persson L. 2008. Resource heterogeneity, diet shifts and intra-cohort competition: effects on size divergence in YOY fish. Oceologica 158: 249-257.

Hussey N.E., Dudley S.F.J., Mccarthy I.D., Cliff G., Fisk A.T. 2011. Stable isotope profiles of large marine predators: viable indicators of tropic position, diet, and movement in sharks? Can. J. Fish. Aquat. Sci. 68: 2029-2045.

Ishihara H., Homma K., Takeda Y., Randall J.E. 1993. Redescription, distribution and food habits of the Indo-Pacific dasyatid stingray Himantura granulata. Japan. J. Ichthyol. 40: 23-28.

Jensen K. 2005. Tapeworms of elasmobranchs (Part I). A monograph on the Lecanicephalidea (Platyhelminthes, Cestoda). Bull. Univ. Nebr. State Mus. 18: 1-241.

Jensen K., Caira J.N., Cielocha J.J., Littlewood D.T.J., WAESCHENBACH A. 2016: When proglottids and scoleces conflict: phylogenetic relationships and a family-level classification of the Lecanicephalidea (Platyhelminthes: Cestoda). Int. J. Parasitol. 46: 291-310.

Jensen K., Mojica K.R., Caira J.N. 2014: A new genus and two new species of lecanicephalidean tapeworms from the striped panray, Zanobatus schoenleinii (Rhinopristiformes: Zanobatidae), off Senegal. Folia Parasitol. 61: 432-440.

Jensen K., Nikolov P., Caira J. N. 2011. A new genus and two new species of Anteroporidae (Cestoda: Lecanicephalidea) from the darkspotted numbfish, Narcine maculata (Torpediniformes: Narcinidae), off Malaysian Borneo. Folia Parasitol. 58: 95-107.

Jensen K., Russell S.L. 2014: Seussapex, a new genus of lecanicephalidean tapeworm (Platyhelminthes: Cestoda) from the stingray genus Himantura (Myliobatiformes: Dasyatidae) in the Indo-West Pacific with investigation of mode of attachment. Folia Parasitol. 61: 231-241.
Last P.R., White W.T., de Carvalho M.R., Séret B., StehMANn F.W., NAYLOR G.J.P. 2016a: Rays of the World. First Edition. Cornell University Press, Ithaca, $790 \mathrm{pp}$.

Last P.R., Naylor G.J.P., Manjaji-Matsumoto B.M. 2016b: A revised classification of the family Dasyatidae (Chondrichthyes: Myliobatiformes) based on new morphological and molecular insights. Zootaxa 4139: 345-368.

Mittelbach G.G., Persson L. 1998: The ontogeny of piscivory and its ecological consequences. Can. J. Fish. Aquat. Sci. 55: 1454-1465.

Mojica K.R., Jensen K., Caira J.N. 2013: Revision of Anteropo$\mathrm{ra}$ (Cestoda: Lecanicephalidea) and descriptions of five new species from stingrays (Myliobatiformes: Dasyatidae) in Borneo. Raffles Bull. Zool. 61: 491-506.

Navia A.F., Torres A., Mejía-Falla P.A., Giraldo A. 2011. Sexual, ontogenetic, temporal and spatial effects on the diet of Urotrygon rogersi (Elasmobranchii: Myliobatiformes). J. Fish Biol. 78: 1213-1224.

Naylor G.J.P., Caira J.N., Jensen K., Rosana K.A.M., Straube N., Lakner C. 2012a: Elasmobranch phylogeny: a mitochondrial estimate based on 595 species. In: J.C. Carrier, J.A. Musick and M.R. Heithaus (Eds.), The Biology of Sharks and Their Relatives. CRC Press, Taylor \& Francis Group, Boca Raton, pp. 31-56.

Naylor G.J.P., Caira J.N., Jensen K., Rosana K.A.M., White W.T., LAST P.R. 2012b: A DNA sequence-based approach to the identification of shark and ray species and its implications for global elasmobranch diversity and parasitology. Bull. Am. Mus. Nat. Hist. 367: 1-262.

Newman A.P., Handy R.D., Gruber S.H. 2012: Ontogenetic diet shifts and prey selection in nursery bound lemon sharks, Negaprion brevirostris, indicate a flexible foraging tactic. Environ. Biol. Fish 95: 115-126.

OкAda S., TANiguchi A. 1971: Size relationship between salmon juveniles in shore waters and their prey animals. Bull. Fac. Fish. Hokkaido Univ. 22: 30-36.

Polis G.A. 1984: Age structure component of niche width and intraspecific resource partitioning: can age groups function as ecological species? Am. Nat. 123: 541-564.

Šantić M., RaĐa B., Pallaoro A. 2013: Feeding habits of brown ray (Raja miraletus Linnaeus, 1758) from the eastern central Adriatic Sea. Mar. Biol. Res. 9: 316-323.

Schaeffner B.C., Beveridge I. 2012: Prochristianella Dollfus, 1946 (Trypanorhyncha: Eutetrarhynchidae) from elasmobranchs off Borneo and Australia, including new records and the description of four new species. Zootaxa 3505: 1-25.

Shiffman D.S., Frazier B.S., Kucklick J.R., Abel D., Brandes J., Sancho G. 2014: Feeding ecology of the sandbar shark in South Carolina estuaries revealed through $\delta 13 \mathrm{C}$ and $\delta 15 \mathrm{~N}$ stable isotope analysis. Mar. Coast. Fish. 6: 156-169.

Spath M.C., Barbini S.A., Figueroa D.E. 2013: Feeding habits of the apron ray, Discopyge tschudii (Elasmobranchii: Narcinidae), from off Uruguay and northern Argentina. J. Mar. Biol. Assoc. U.K. 93: 291-297.

Subhapradha C. 1955: Cestode parasites of fishes of Madras Coast. Ind. J. Helminthol. 7: 41-132.

Williams H.H. 1964: Some new and little known cestodes from Australian elasmobranchs with a brief discussion on their possible use in problems of host taxonomy. J. Parasitol. 54: 737-748.

Yamaguti S. 1934. Studies on the helminth fauna of Japan. Part 4. Cestodes of fishes. Jpn. J. Zool. 6: 1-112.

Cite this article as: Herzog K.S., Jensen K. 2017: A new genus with two new species of lecanicephalidean tapeworms (Cestoda) from the Mangrove Whipray, Urogymnus granulatus (Myliobatiformes: Dasyatidae) from the Solomon Islands and Northern Australia. Folia Parasitol. 64: 004. 